\title{
Induced Trisomics in Chrysanthemum coronarium Linn.
}

\author{
R.C. Gupta and B.S. Gill \\ Department of Botany, Punjabi University, Patiala-147 002, India
}

Received September 9, 1983

Chrysanthemum coronarium, a commonly cultivated winter ornamental, is diploid $(\mathrm{n}=9)$ with fairly high incidence of structural heterozygosity. As many as 16 chromosomes are sometimes involved in reciprocal translocations with maximum of eight chromosomes in a single association (Gill and Gupta 1981). Colchicine treatment was given to seeds and seedlings for the artificial induction of autopolyploidy with the purpose to understand its effect on ornamental characteristics and structural heterozygosity. As a consequence of this two hypertriploids ( $2 n=28$ and $30)$ and one mixoploid $(2 n=16,18)$ were obtained, besides many autotetraploids $(2 n=36)$. Two singly trisomics $(2 n=19)$ and one doubly trisomic $(2 n=20)$ were recovered from the open pollinated progeny of one hypertriploid $(2 n=30)$. The present communication deals with the transmission of trisomy and the cytomorphology of these trisomics.

\section{Material and methods}

Smears for appropriate sized capitula were made in $1 \%$ acetocarmine. Pollen fertility was estimated by mounting mature pollen grains in glycero-acetocarmine.

\section{Results}

\section{Morphology}

Both the singly as well as doubly trisomics are not found to have any appreciable morphological difference as compared with the normal plants. Comparison of stomatal and pollen characters of these trisomics is given in Table 1. It could not be ascertained whether the two singly trisomics have trisomy for the same or for different chromosomes. Therefore, it is preferred to refer them as trisomic A and $\mathrm{B}$.

\section{Cytology}

In trisomic $\mathrm{A}$, besides bivalents, univalents and multiple associations of 3 and 4 chromosomes exist with an averge frequency per PMC of 8.32, 0.54, 0.50 and 0.08 , respectively (Table 2) (Figs. 1-3). Chiasma frequency which ranges from 16-18, is 17.036 per cell and 0.897 per chromosome.

In trisomic $B$, the number of bivalents and univalents ranges 6-9 and 0-3 with average frequency being 7.38 and 0.42 , respectively. Single multiple association which is represented in $88.46 \%$ of PMCs, has variable number of chromosomes 
Table 1. Stomatal and pollen characters of diploid and trisomics

\begin{tabular}{|c|c|c|c|c|}
\hline \multirow{3}{*}{ Character } & \multirow{3}{*}{ Diploid } & \multicolumn{3}{|c|}{ Trisomics } \\
\hline & & \multicolumn{2}{|c|}{ Singly $(2 n=19)$} & \multirow{2}{*}{$\begin{array}{l}\text { Doubly } \\
(2 n=20)\end{array}$} \\
\hline & & A & B & \\
\hline \multicolumn{5}{|l|}{ Stomatal size } \\
\hline \multirow[t]{2}{*}{ Upper epidermis } & $42.9-56.5 \times$ & $35.1-46.8 \times$ & - & $35.1-46.8 \mu \mathrm{m}$ \\
\hline & $29.2-39.0 \mu \mathrm{m}$ & $\begin{array}{l}27.3-33.1 \mu \mathrm{m} \\
31.2-40.9 \times\end{array}$ & $31.0-54.0 x$ & $\begin{array}{l}29.2-33.1 \mu \mathrm{m} \\
39.0-62.4 \times\end{array}$ \\
\hline Lower epidermis & $27.3-50.7 \mu \mathrm{m}$ & $27.3-31.2 \mu \mathrm{m}$ & $23.0-35.0 \mu \mathrm{m}$ & $27.3-50.7 \mu \mathrm{m}$ \\
\hline \multicolumn{5}{|l|}{ Stomatal frequency } \\
\hline Lower epidermis & $103.1 / \mathrm{mm}^{2}$ & $146.4 / \mathrm{mm}^{2}$ & $88.5 / \mathrm{mm}^{2}$ & $122.2 / \mathrm{mm}^{2}$ \\
\hline \multicolumn{5}{|l|}{ Stomata index } \\
\hline Lower epidermis & 23.8 & 24.2 & 22.2 & 27.2 \\
\hline Pollen size & $27.3-31.2 \mu \mathrm{m}$ & $27.3-39.0 \mu \mathrm{m}$ & $22.4-33.1 \mu \mathrm{m}$ & $25.3-42.9 \mu \mathrm{m}$ \\
\hline Pollen fertility & $95 \%$ & $90 \%$ & $85 \%$ & $92 \%$ \\
\hline
\end{tabular}

Table 2. Chromosomal associations at diakinesis and metaphase I

\begin{tabular}{|c|c|c|c|c|c|c|c|}
\hline \multirow{2}{*}{ Taxa } & & \multicolumn{6}{|c|}{ Chromosomal associations } \\
\hline & & VII & $\mathrm{V}$ & IV & III & II & I \\
\hline \multirow{4}{*}{$\begin{array}{l}\text { Trisomic A } \\
\text { (PMCs observed 50) }\end{array}$} & Range & - & - & $0-1$ & $0-1$ & $6-9$ & $0-3$ \\
\hline & Total & - & - & 4 & 25 & 416 & 27 \\
\hline & $\begin{array}{l}\text { Average } \\
\text { frequency/PMC }\end{array}$ & - & - & 0.08 & 0.50 & 8.32 & 0.54 \\
\hline & $\begin{array}{l}\% \text { age of } \\
\text { chromosomes } \\
\text { involved }\end{array}$ & - & - & 1.68 & 7.89 & 87.58 & 2.84 \\
\hline \multirow{4}{*}{$\begin{array}{l}\text { Trisomic B } \\
\qquad \text { (PMCs observed 26) }\end{array}$} & Range & $0-1$ & $0-1$ & $0-1$ & $0-1$ & $6-9$ & $0-3$ \\
\hline & Total & 2 & 9 & 4 & 8 & 192 & 11 \\
\hline & $\begin{array}{l}\text { Average } \\
\text { frequency/PMC }\end{array}$ & 0.08 & 0.35 & 0.15 & 0.31 & 7.38 & 0.42 \\
\hline & $\begin{array}{l}\% \text { age of } \\
\text { chromosomes } \\
\text { involved }\end{array}$ & 2.95 & 9.21 & 3.16 & 4.89 & 77.68 & 2.21 \\
\hline \multirow{4}{*}{$\begin{array}{l}\text { Doubly trisomic } \\
\qquad \text { (PMCs observed 51) }\end{array}$} & Range & - & - & $0-2$ & $0-2$ & $6-10$ & $0-2$ \\
\hline & Total & - & - & 3 & 54 & 403 & 40 \\
\hline & $\begin{array}{l}\text { Average } \\
\text { frequency/PMC }\end{array}$ & - & - & 0.06 & 1.06 & 7.90 & 0.78 \\
\hline & $\begin{array}{l}\% \text { age of } \\
\text { chromosomes } \\
\text { involved }\end{array}$ & - & - & 1.20 & 15.90 & 79.00 & 3.90 \\
\hline
\end{tabular}

Figs. 1-16. 1-3. Singly trisomic A. 1, MI, $\mathrm{I}_{\mathrm{III}}+8_{\mathrm{II}}$. 2, MI, $9_{\mathrm{II}}+1_{\mathrm{I}}$. 3, diakinesis with 'frying pan' trivalent and 8 bivalents. 4-7. Singly trisomic B. 4, MI, $\mathrm{I}_{\nabla}+7_{\mathrm{II}} .5, \mathrm{MI}, \mathrm{I}_{\mathrm{V}}+7_{\mathrm{II}}$ with one chromosome of a bivalent fragmented. $6, \mathrm{MI}, \mathrm{I}_{\mathrm{IV}}+7_{\mathrm{II}}+1_{\mathrm{I}} \cdot 7, \mathrm{MI}$, diakinesis, $\mathrm{I}_{\mathrm{VII}}+$ 6. 8, 9: Doubly trisomic. 8, MI, $2_{\mathrm{III}}+7_{\mathrm{II}}$. 9, MI, $1_{\mathrm{III}}+8_{\mathrm{II}}+1_{\mathrm{I}}$. 10-12: Trisomic A. 10 , AII with $10: 10: 9: 9$ chromosomes at the poles. 11 , MII with 9 two chromatids chromosomes 


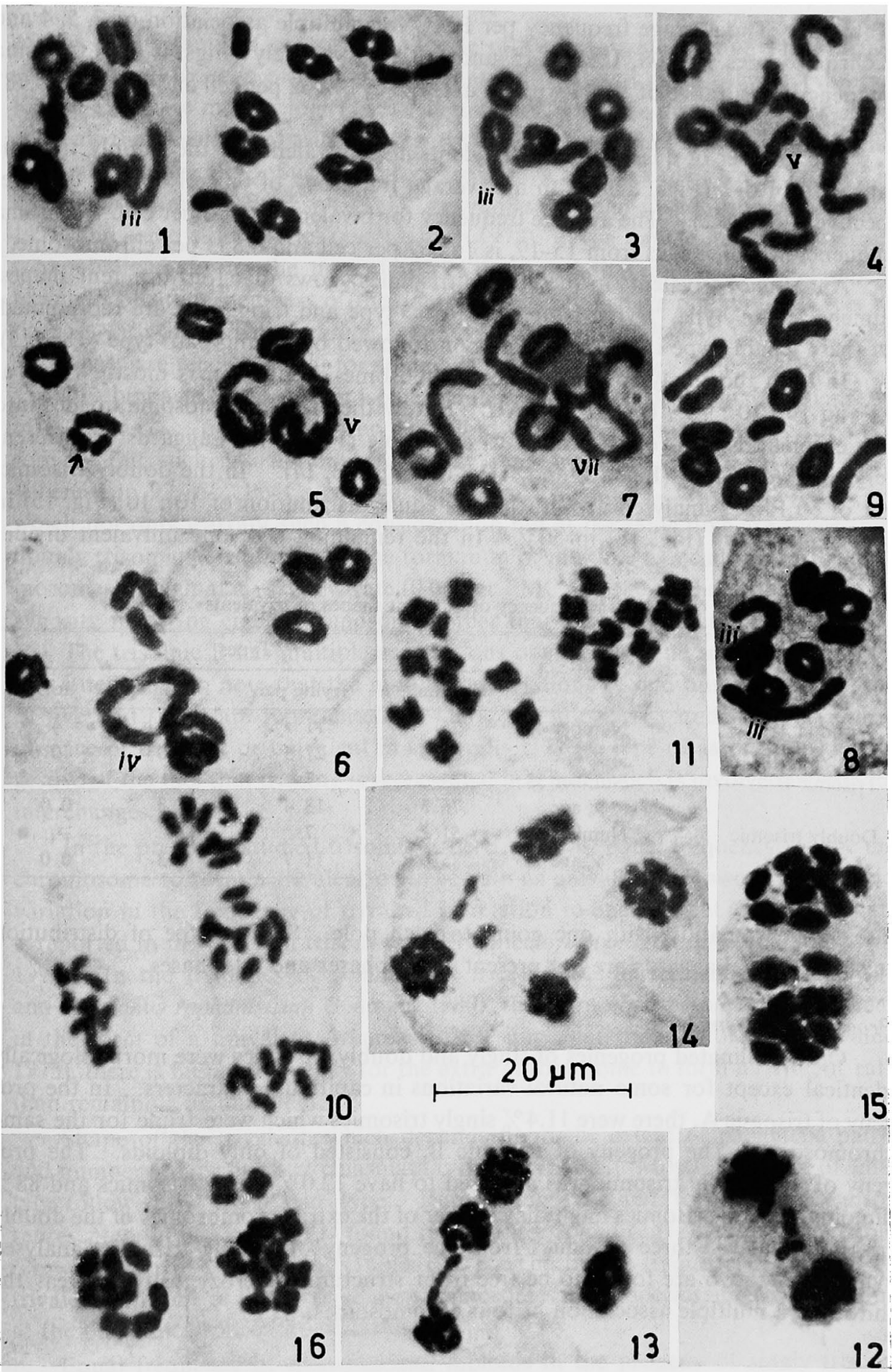

and 1 one chromatid chromosome in each nuclear plate. 12, TI with laggards. 13, 14: Trisomic B. 13, TII with chromosome bridge. 14, TII with laggards. 15-16: Doubly trisomic. 15, AI with $10: 10$ chromosomes. 16 , AI with $11: 9$ chromosomes. 
(Table 2). The average frequency per PMC for multiple association of 7, 5, 4 and 3 chromosomes is $0.08,0.35,0.15$ and 0.31 , respectively (Figs. 4-7). Chiasma frequency has a range of 13-17 with an average of 14.962 per cell and works to 0.787 per chromosome.

The number of quadrivalents, trivalents and univalents in the doubly trisomic ranges from $0-2$ (Figs. 8,9) with an average frequency of $0.06,1.06$ and 0.78 , respectively (Table 2). The average frequency for bivalents is 7.90 per cell. Chiasma frequency which ranges from $15-19$, is 16.659 per cell and 0.833 per chromosome.

Analysis of trivalents in these three trisomics shows that four different shapes, namely, 'chain' type, 'frying pan' type, 'fork' type and 'ring' type are represented. Of these 'chain' type is the most common followed by 'frying pan' type (Table 3).

In both the singly trisomics, the chromosome distribution is mostly $10: 9$ at AI and $10: 10: 9: 9$ (Fig. 10) at AII. Rarely the extra chromosome divides into two chromatids with one included to each pole (Fig. 11). Laggards are present very rarely at AI/TI (Fig. 12) and AII/TII (Figs. 13, 14). In the doubly trisomic, out of 50 PMCs analysed at A-I, there is equal distribution of $10: 10$ (Fig. 15) in $44 \%$ and $11: 9$ (Fig. 16) in $50 \%$. In the remaining $6 \%$, one univalent divides

Table 3. Frequency of different shapes of trivalents

\begin{tabular}{lccccc}
\hline \multirow{2}{*}{ Taxa } & \multirow{2}{*}{$\begin{array}{c}\text { Trivalents } \\
\text { observed }\end{array}$} & \multicolumn{4}{c}{ Types } \\
\cline { 5 - 6 } & & 'chain' & 'frying pan' & 'ring' & 'fork' \\
\hline Trisomic A & Number 40 & 25 & 11 & - & 4 \\
& $\%$ age & 62.5 & 27.5 & 0.0 & 10.0 \\
Trisomic B & Number 38 & 29 & 7 & 2 & - \\
& $\%$ age & 76.3 & 18.4 & 5.3 & 0.0 \\
Doubly trisomic & Number 60 & 51 & 7 & 2 & - \\
& $\%$ age & 85.0 & 11.7 & 3.3 & 0.0 \\
\hline
\end{tabular}

into two chromatids, with one going to each pole. Similar type of distribution exists at AII. Laggards are not present at anaphases and telophases.

\section{Progeny of trisomics}

Open pollinated progenies of singly and doubly trisomics were morphologically identical except for some natural variations in capitulum characters. In the progeny of trisomic $\mathrm{A}$, there were $11.4 \%$ singly trisomics which were triple for the same chromosome. The progeny of trisomic B, consisted of only diploids. The progeny of the doubly trisomic was analysed to have $12.0 \%$ singly trisomics and $88 \%$ diploids. These trisomics might have either of the extra chromosomes of the doubly trisomic. Of the three trisomics from the progeny of doubly trisomic, analysed cytologically, two are found to be free from structural heterozygosity whereas the third had a multiple association of four chromosomes.

\section{Discussion}

Prior to the present studies, there is no report of experimentally produced tri- 
somics in the family Compositae. Those of Verbena tenuisecta (Arora and Khoshoo 1969), Trigonella corniculata (Singh et al. 1978) and many other species (vide: Khush 1973) are morphologically distinguishable from the normal diploids. However, all the trisomics obtained presently in Chrysanthemum coronarium are indistinct morphologically. Such trisomics are known to have been obtained in Solanum tuberosum (Lam and Erickson 1971), Amaranthus tricolor (Madhusoodanan and Pal 1976) and some other species (vide: Khush 1973). As a limited number of trisomics were obtained during the present work, the possibility cannot be ruled out that trisomics of other members of the complement may behave differently as has been the case with Gossypium hirsutum, Zea mays and species of Petunia where phenotypic differences are recorded only for some of the trisomics (vide: Khush 1973).

On the basis of the chromosome number and the chromosomal configurations of $\mathrm{I}_{\mathrm{IV}}+8_{\mathrm{II}}, 2_{\mathrm{IV}}+6_{\mathrm{II}}$ and $10_{\mathrm{II}}$, the aneuploid with $2 \mathrm{n}=20$ might be taken as tetrasomic. But such associations are hardly represented in $7.84 \%$ of the PMCs. Whereas in $92.16 \%$ PMCs configurations are $\mathrm{I}_{\mathrm{III}}+8_{\mathrm{II}}+1_{\mathrm{i}} .2_{\mathrm{III}}+7_{\mathrm{II}}$ and $9_{\mathrm{II}}+2_{\mathrm{I}}$, which not only warrant such a consideration but at the same time are suggestive of doubly trisomic constitution. The formation of multiple associations of four chromosomes though at a very low rate $(0.06$ per PMC), is due to the structural heterozygosity involving eight chromosomes other than those representing trisomy.

The trisomic B has multiple associations of four, five and seven chromosomes. It is interesting to note that the multiple associations of odd number such as those of five and seven are represented in $42.31 \%$ of the PMCs and there is complete absence of trivalent or univalent in such cells. These type of associations are suggestive of the fact that trisomy is represented in a pair which is involved in structural interchanges.

In the presently studied trisomics, there is almost equal frequency for the extra chromosome to form a trivalent or to remain as univalent. However, tremendous variation in the frequency of trivalent in relation to one bivalent and one univalent is reported in the different trisomics of Trigonella foenum-graecum (Singh and Singh 1976). In the trisomics of Amaranthus tricolor (Madhusoodanan and Pal 1976) and Raphanus raphanistrum (Kamala 1980), the extra chromosome mostly remains in the form of a univalent, whereas in the nucleolar trisomic of maize (Ghidoni 1975), there is higher frequency for the extra chromosome to form a trivalent rather than remaining as univalent.

Shape of the trivalent, which depends upon the extent of pachytene pairing, and number and position of chiasmata is quite variable. Mostly these are of 'chain' type followed by 'frying pan' type. Rarely 'ring' type and 'fork' type may also be represented. Similar trend is found in the autotriploid $(2 n=27)$ and hypertriploid $(2 n=30)$ taxa of the species (Gupta 1981). The higher frequency of 'chain' type trivalents, in spite of large size of the chromosomes in the species, might be attributed to the distal localization of chiasmata.

Equal frequency of trisomics and diploids in the progeny of singly trisomics and about $25 \%$ doubly trisomics, $50 \%$ singly trisomics and $25 \%$ diploids in that of doubly trisomic are expected if anaphase distribution in megasporogenesis is on the pattern of microsporogenesis. However, all the individuals of the progeny of one 
of the singly trisomic were diploids and the frequency of trisomics was rather low $(12 \%)$ in those of doubly and other singly trisomic. The low rate of transmission of the extra chromosome cannot be attributed to its elimination during meiosis. Probably the reduced transmission is due to the functional inviability of the aneuploid gametes caused by extra chromosome (Satina et al. 1938, Khush and Rick 1969). Besides, non-viability of $2 n+1$ zygote embryo might be the other reason for the low incidence of trisomics (vide: Khush 1973). As such there seems to be little chances of exploiting aneuploidy as a method of improving the floriculture characteristics of the species in which structural heterozygosity might not favour the establishment of aneuploidy even at diploid level.

\section{Summary}

Two singly trisomics $(2 \mathrm{n}=19)$ and one doubly trisomic $(2 \mathrm{n}=20)$ were obtained in the open pollinated progeny of the colchicine induced hypertriploid $(2 n=30)$ of Chrysanthemum coronarium. Open pollinated progeny of one singly trisomic consisted of diploids only whereas the frequency of trisomics was rather low (12\%) in the progeny of other trisomics. Trisomy is found to have no morphological effect. In about $50 \%$ of the PMCs, the extra chromosome constitutes a trivalent. In one singly trisomic, interchanges also involve the triple chromosome leading to the formation of multiple association of five and seven chromosomes.

\section{Acknowledgements}

We are grateful to Professor S. S. Bir, F. N. A., Department of Botany, Punjabi University, Patiala for encouragement. Financial assistance to the senior author from C.S.I.R. and U.G.C., New Delhi is highly acknowledged.

\section{References}

Arora, O. P. and Khoshoo, T. N. 1969. Primary trisomics in moss verbena. Euphytica 18: 237248.

Ghidoni, A. 1975. Inheritance of the nucleolar trisome in Zea mays L. Caryologia 28: 237-250.

Gill, B. S. and Gupta, R. C. 1891 . Structural hybridity in Chrysanthemum coronarium L. In Manna, G. K. and Sinha, U. (Eds.) Perspectives in Cytology and Genetics 3: 523-530.

Gupta, R. C. 1981. Cytological investigations on some Indian Compositae. Ph. D. thesis submitted to Punjabi University, Patiala.

Kamala, T. 1980. Trisomics in Raphanus raphanistrum L. Jour. Indian Bot. Soc. 59: 17-19. Khush, G. S. 1973. Cytogenetics of Aneuploids. Academic Press, New York.

- and Rick, C. M. 1969. Tomato secondary trisomics: origin, identification, morphology and use in cytogenetic analysis of tomato genome. Heredity 24: 129-146.

Lam, S. L. and Erickson, H. T. 1971. The nucleolar trisomic and trisomic transmission in a diploid potato. J. Heredity 62: 375-376.

Madhusoodanan, K. J. and Pal, M. 1976. A primary trisomic in Amaranthus trcolor Linn. New Botanist 3: 70-73.

Satina, S., Blakeslee, A. F. and Avery, A. G. 1938. Chromosomal behaviour in triploid Datura III. The seed. Amer. J. Bot. 25: 595-602. 
Singh, D. and Singh, A. 1976. Primary trisomics in Trigonella foenum-graecum. Nucleus 19: 91-95.

-, - and Roy, R. P. 1978. Primary trisomics of Trigonella corniculata. I. Morphology and identification. Caryologia 31: 355-361. 